\title{
A Computational Comparison of Ether and Ester Electrolyte Stability on a Ca Metal Anode
}

\author{
Diana Liepinya $\mathbb{D D}^{1,2}$ and Manuel Smeu ${ }^{1}{ }^{1}$ \\ ${ }^{1}$ Department of Physics, Binghamton University, Binghamton, NY, USA \\ ${ }^{2}$ Department of Materials Science and Engineering, University of Maryland, College Park, MD, USA
}

Correspondence should be addressed to Manuel Smeu; msmeu@binghamton.edu

Received 2 May 2021; Accepted 9 August 2021; Published 12 October 2021

Copyright ( 2021 Diana Liepinya and Manuel Smeu. Exclusive Licensee Beijing Institute of Technology Press. Distributed under a Creative Commons Attribution License (CC BY 4.0).

Ca-ion batteries (CIBs) have the potential to provide inexpensive energy storage, but their realization is impeded by the lack of suitable electrolytes. Motivated by recent experimental progress, we perform ab initio molecular dynamics simulations to investigate early decomposition reactions at the anode-electrolyte interface. By examining different combinations of solvent-tetrahydrofuran (THF) or ethylene carbonate (EC) - and salt- $\mathrm{Ca}\left(\mathrm{BH}_{4}\right)_{2}, \mathrm{Ca}\left(\mathrm{BF}_{4}\right)_{2}, \mathrm{Ca}\left(\mathrm{BCl}_{4}\right)_{2}$, and $\mathrm{Ca}\left(\mathrm{ClO}_{4}\right)_{2}$ - we identify a variety of behavioral trends between electrolyte solutions. Next, we perform a separate trajectory with pure THF and gradually increased negative charge; despite an addition of -32e, no THF decomposition is detected. Charge analysis reveals that in a reductive environment, THF distributes excess charge evenly across its hydrocarbon backbone, while EC concentrates charge on its ester oxygens and carbonyl carbon, resulting in decomposition. Graphs of charge vs. time for both solvents reveal that EC decomposition products can be reduced by up to five electrons, while those of THF are limited to a single electron. Ultimately, we find $\mathrm{Ca}\left(\mathrm{BH}_{4}\right)_{2}$ and THF to be the most stable solution investigated herein, corroborating experimental evidence of its suitability as a CIB electrolyte.

\section{Introduction}

Li-ion batteries (LIBs) are ubiquitous in current technology, powering a variety of devices ranging from portable electronics to electric vehicles. However, the scarcity of their component elements, namely, $\mathrm{Li}$ and $\mathrm{Co}$, makes them an imperfect choice for meeting rapidly growing battery demands [1]; these components make LIBs prohibitively expensive in large-scale applications like grid energy storage [2]. Further concerns-including dendritic plating behavior, the lower melting point of $\mathrm{Li}$ metal, safety issues, and an approaching performance ceiling-motivate the development of an alternative technology [3, 4]. Assuming the development of an affordable cathode, Ca-ion batteries (CIBs) could significantly improve upon the cost of current battery technology due to the much lower price of Ca metal relative to Li metal [3]. Theoretically, CIBs could also provide performance benefits relative to LIBs. Due to its divalent nature, $\mathrm{Ca}^{2+}$ can provide higher volumetric capacity than $\mathrm{Li}^{+} . \mathrm{Ca}^{2+}$ also has a very low redox potential relative to SHE-nearly that of $\mathrm{Li}^{+}-\mathrm{a}$ feature that allows theoretical CIBs to have higher volumetric (and, with certain cathodes, gravimetric) energy density than LIBs [5]. Although multivalent ions can suffer from high diffusion barriers due to their increased charge density, the large ionic radius of $\mathrm{Ca}$ offsets these issues $[4,6]$.

Despite these benefits, unfavorable electrolyte decomposition at the anode has historically discouraged CIB development $[4,7]$. In an ideal case, decomposition products would form a protective, cation-conducting interface that prevents further degradation of both anode and electrolyte. Also known as the solid-electrolyte interphase (SEI) [8], this layer allows for the high cyclability of successful LIBs. In 1991, Aurbach et al. famously concluded that although a similar layer forms in Ca-ion batteries, it does not allow for Ca-ion conduction, therefore passivating the anode and preventing $\mathrm{Ca}$ plating [9]. While Aurbach et al. reported successful stripping in select systems, these results discouraged further attempts at Ca-ion plating/stripping, and no working systems were reported until the results of Ponrouch et al. in 2016 [7]. 
Since the publication of Ponrouch et al., there have been numerous reports of viable $\mathrm{Ca}$-ion electrolytes, ranging from organic solvents [10-14] to ionic liquids $[15,16]$ and polymers [17]. With several examples of successful Ca-ion cathodes [18-21], a cyclable Ca-ion rocking chair battery is within reach; in fact, there are already some functional examples of such a setup $[14,22]$. These successes motivate further investigation of CIB electrolytes, which remain a limiting factor in battery performance.

Although there are now several examples of viable CIB electrolytes, these solutions are far from perfect. Several of them display dendritic plating behavior [13, 23, 24], while solution viscosity, salt solubility, ion diffusion, and dissolution barriers (as dictated by coordination number and ion pair frequency) continue to limit the rate capability and capacity of CIBs [5, 25-28]. Perhaps most significantly, interface formation mechanisms and components remain largely unelucidated, even when they are one of the most significant factors controlling battery performance $[13,26]$. We aim to address this outstanding issue by means of ab initio molecular dynamics (AIMD), allowing us to observe preliminary interfacial decomposition products under a variety of conditions.

In choosing our electrolyte composition, we focus on polar aprotic solvents because they have a sufficient electrochemical window, minimize solution viscosity, and provide a dielectric constant high enough to dissolve many salts [7]. In addition to meeting these criteria, our first solvent, ethylene carbonate (EC), was chosen for its popularity in computational and experimental CIB research $[7,11,25$, 29]. Despite a narrower electrochemical window, we choose tetrahydrofuran (THF) for our second solvent. In preliminary investigations, THF showed remarkable stability, suggesting that this solvent may be less prone to parasitic reactions and passivating product formation, possibly leading to the room-temperature CIB cyclability seen by Wang et al. [10]. In combination with these two solvents, we also consider four different salts: $\mathrm{Ca}\left(\mathrm{BH}_{4}\right)_{2}, \mathrm{Ca}\left(\mathrm{BF}_{4}\right)_{2}, \mathrm{Ca}\left(\mathrm{BCl}_{4}\right)_{2}$, and $\mathrm{Ca}\left(\mathrm{ClO}_{4}\right)_{2}$. All but $\mathrm{Ca}\left(\mathrm{BCl}_{4}\right)_{2}$ have been used in experiment [7, 9-12], allowing us to elucidate experimental results while also investigating a new salt. In order to simulate the effects of excess negative charge experienced during cycling, we also include a trajectory of pure THF with a Ca anode and a gradually increasing excess negative charge.

\section{Computational Methods}

Our simulations employed ab initio molecular dynamics (AIMD) [30] to track molecular motion and chemical reactions at the anode-electrolyte interface on the order of $10^{-11} \mathrm{~s}$. These calculations were executed in the Vienna ab initio Simulation Package (VASP) [31-33] using projector augmented wave (PAW) potentials [34] and the PerdewBurke-Ernzerhof (PBE) exchange-correlation functional [35]. All AIMD were performed using a single $\Gamma k$-point, a $400 \mathrm{eV}$ plane wave cutoff, and a temperature of $450 \mathrm{~K}$, fixed using a Nosé thermostat. We selected a time step of $1 \mathrm{fs}$, necessitating the use of a deuterium mass for all $\mathrm{H}$ atoms.
All simulation cells featured a Ca metal anode made of a $3 \times 4 \times 6$ repetition of a $\mathrm{Ca}$ unit cell. This slab was relaxed with a $15 \AA$ vacuum in the $z$ direction using a $450 \mathrm{eV}$ plane wave cutoff and $5 \times 3 \times 3 k$-mesh. Both parameters were selected to be converged within $1 \mathrm{meV} /$ atom. The two middle layers of the slab were frozen in order to preserve the crystal structure of $\mathrm{Ca}$ metal, leaving two mobile layers on either surface of the anode. An electrolyte of fixed volume was placed above the anode such that all molecules were at least $2.31 \AA$ above the electrode surface, a distance equal to the van der Waals radius of $\mathrm{Ca}$ metal. The resultant simulation cell with dimensions of $11.05 \AA \times 16.58 \AA \times 40.34 \AA$ is shown in Figure 1(a). The electrolyte was obtained by manually arranging the desired number of solvent atoms in a cell of approximately twice the final volume. Three solvent molecules were each replaced with a salt ion pair to obtain a salt concentration of $1.2 \mathrm{M}$. This process yielded either 33 EC molecules or 27 THF molecules in each cell in accordance with each solvent's liquid density. AIMD was performed for $500 \mathrm{fs}$ to allow for molecule repositioning, after which the cell dimensions were decreased; this was repeated four times until the desired dimensions were reached. Electrode-electrolyte simulations were run for a total of 10 ps. Repeat simulations of 5 ps were performed for $\mathrm{Ca}\left(\mathrm{BCl}_{4}\right)_{2} / \mathrm{THF}$ and $\mathrm{Ca}\left(\mathrm{ClO}_{4}\right)_{2} / \mathrm{THF}$ to investigate the effect of initial solvent orientation. An analogous approach was taken to construct two electrode-electrolyte systems without salts, one each for EC and THF; the latter is shown in Figure 1(b). Solvent count was decreased to either 19 EC or 16 THF molecules in order to economically extend these trajectories to $20 \mathrm{ps}$, resulting in final dimensions of $11.05 \AA \times 16.58 \AA \times 30.34 \AA$. Lastly, a final trajectory was performed wherein a single electron was added to the pure THF system every $500 \mathrm{fs}$ until a total charge of $-30 e$ was reached. The system was held at this charged state for an additional 10 ps. This process was based off the work of CamachoForero and Balbuena [36]. The DDEC6 Chargemol program $[37,38]$ was chosen to analyze charge localization in certain AIMD trajectories, including an in-depth characterization of select decomposition reactions. Additionally, time-dependent density of states (TD-DOS) was plotted for individual solvent molecules in the neutral pure solvent simulations to investigate differences in EC and THF stability. This approach was modeled after Yamijala et al. [39].

\section{Results}

3.1. Establishing Solvent Behavior. In order to define a baseline for solvent behavior, we first investigated two 20 ps AIMD trajectories of either pure EC or pure THF with a $\mathrm{Ca}$ anode. EC appeared completely unstable on the Ca metal surface, undergoing rapid decomposition upon contact with the anode; of the 19 molecules, 12 decomposed by the end of the trajectory, eight of which reacted within the first 4 ps. This trend is visually represented in Fig. S1, which displays a plot of the total number of decomposed EC molecules over time. All decomposition proceeded via the two-step reduction shown in Figure 2(e), forming $\mathrm{CO}$ and $\mathrm{C}_{2} \mathrm{H}_{4} \mathrm{O}_{2}{ }^{2-}$. All EC molecules decomposed with the carbonyl group facing 


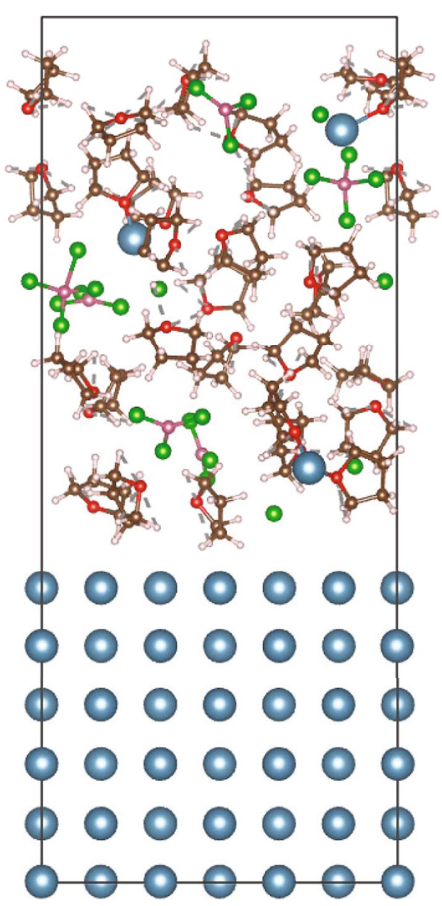

(a)

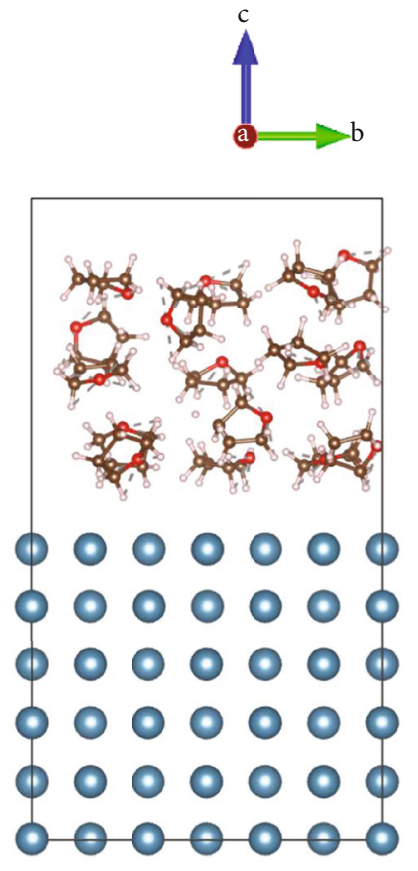

(b)

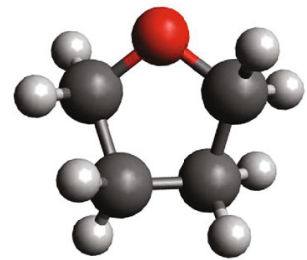

THF

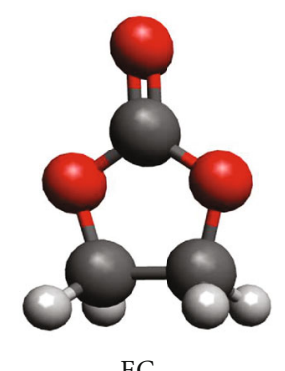

(c)

$\begin{array}{ll}\mathrm{C} & \mathrm{Ca} \\ \mathrm{H} & \mathrm{B} \\ \mathrm{O} & \mathrm{Cl}\end{array}$

FIGURE 1: Sample simulation cells for AIMD trajectories of (a) THF with $\mathrm{Ca}\left(\mathrm{BCl}_{4}\right)_{2}$ and (b) pure THF alongside (c) individual THF and EC molecules. These cells are representative of all systems with and without salt, respectively.

the anode, as shown in Fig. S2; this trend became more pronounced in molecules that decomposed later. $\mathrm{CO}$ decomposed further to form a Ca-O-C matrix, while $\mathrm{C}_{2} \mathrm{H}_{4} \mathrm{O}_{2}^{2-}$ coated the anode surface. Figure 2(a), which displays the $z$ -component of atomic positions in the simulation cell as a function of time, shows that the majority of interface evolution is complete after $4 \mathrm{ps}$. This is consistent with the decomposition time noted above. These results corroborate the findings of Young and Smeu, who report 10 ps of data in a similar simulation cell [29]. In contrast with EC, THF proved to be strikingly stable throughout the duration of the simulation. Remarkably, both solvent and anode remain intact at the 20 ps mark; the clear separation between these two components is particularly evident in Figure 2(b). The solvent is further segmented into three distinct layers; interaction with the anode creates a layer at each interface, leaving a restricted space for the remaining THF molecules to occupy. The bright red band at either interface in Figure 2(b) shows how the THF molecules preferentially orient with the oxygen towards the anode.

3.2. Effects of Salts. Having established a baseline for molecule reactivity, we may now compare the behavior of salts in these solutions. In the following trajectories, salts appeared to have marginal effects on solvent reactivity. Early in the time-dependent decomposition of EC (Figure 3), it appears that $\mathrm{Ca}\left(\mathrm{BF} 4_{4}\right)_{2}$ and $\mathrm{Ca}\left(\mathrm{BCl}_{4}\right)_{2}$ cause faster decomposition, but this difference disappears after 2 ps. By the end of the simulation, only $\mathrm{Ca}\left(\mathrm{ClO}_{4}\right)_{2}$ resulted in a significant decrease in EC decomposition, yielding a total of 8 decomposed molecules after $10 \mathrm{ps}, 3$ fewer than the pure solvent reference. This was likely due to increased anode passivation from $\mathrm{ClO}_{4}^{-}$decomposition; analogous anion decomposition was less frequent with the other salts. In addition to altering total decomposition, certain salts also triggered new reaction pathways. In the presence of $\mathrm{Ca}\left(\mathrm{BF}_{4}\right)_{2}, \mathrm{Ca}\left(\mathrm{BCl}_{4}\right)_{2}$, and $\mathrm{Ca}\left(\mathrm{ClO}_{4}\right)_{2}$, one $\mathrm{EC}$ molecule decomposed as shown in Figure 2(f), forming $\mathrm{CO}_{3}{ }^{2-}$ and $\mathrm{C}_{2} \mathrm{H}_{4}$ within the first picosecond of the simulation. In all cases, this molecule was located on the anode surface and directly adjacent to a salt ion pair.

Much like EC, THF stability was only slightly affected by the salt selection. The sole instance of THF decomposition was recorded in the presence of $\mathrm{Ca}\left(\mathrm{BCl}_{4}\right)_{2}$. The molecule in question was on the anode surface and in contact with one salt ion pair. Immediately upon simulation start, the THF ring opened at an ester bond. At approximately $3000 \mathrm{fs}$, the molecule's ring closed once more around a boron atom originating from a decomposed $\mathrm{BCl}_{4}^{-}$to form $\mathrm{C}_{4} \mathrm{H}_{8} \mathrm{OB}$. A THF/Ca $\left(\mathrm{BCl}_{4}\right)_{2}$ trajectory with an alternate starting orientation was run for 5 ps but did not yield any decomposition. Both the decomposed solvent molecules as well as their resulting products are described in the "Solvent molecules" column of Table 1 .

Unlike solvent stability, inorganic decomposition products were significantly affected by salt choice. Original 


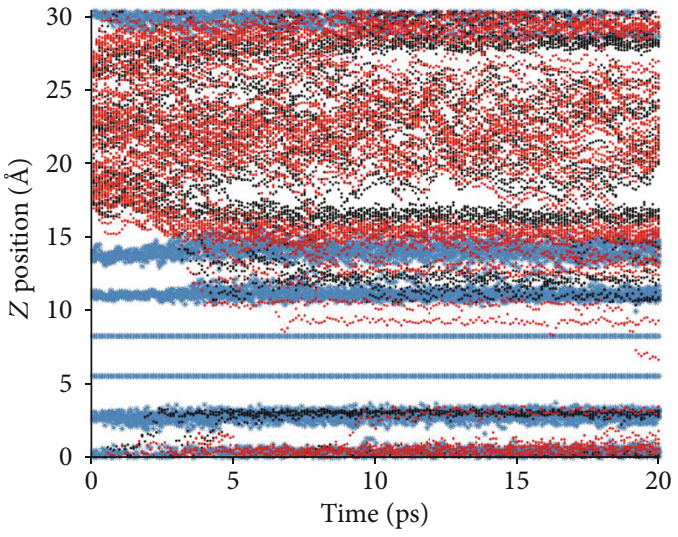

(a)
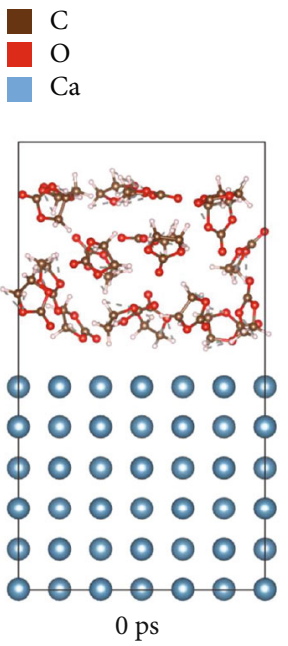

(c)
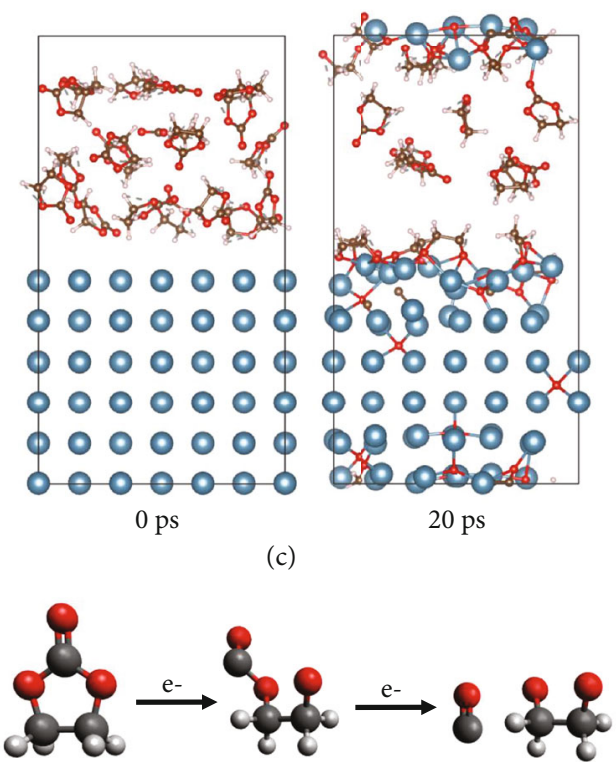

(e)

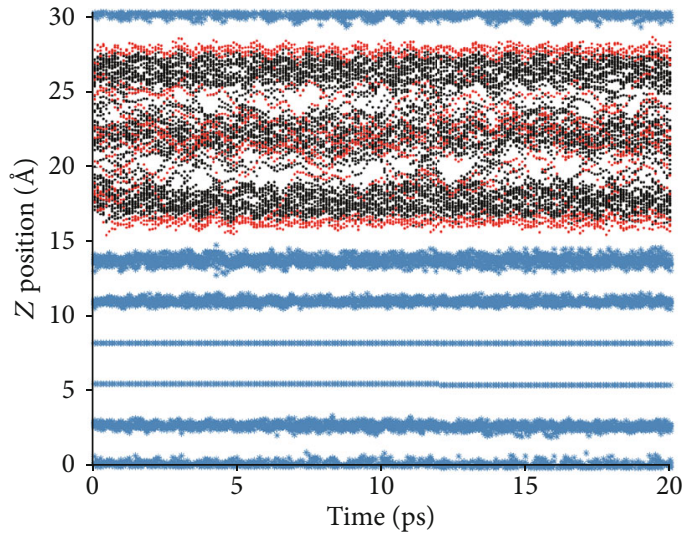

(b)

\section{$\mathrm{C}$
$\mathrm{O}$
$\mathrm{Ca}$}

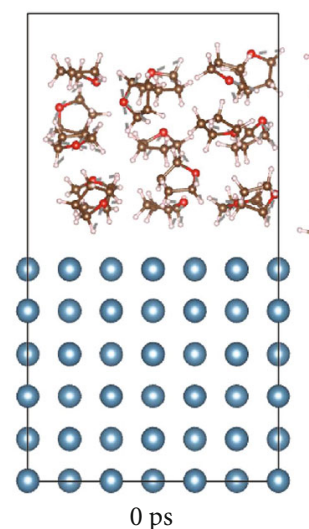

(d)
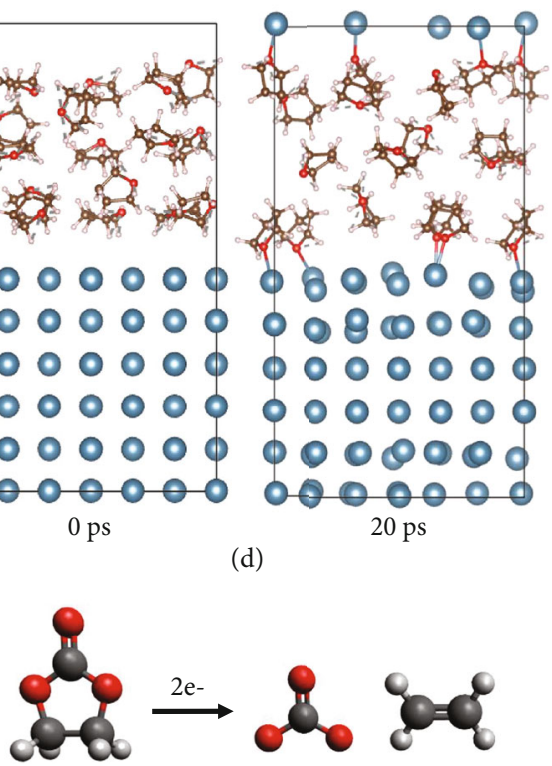

(f)

Figure 2: C (black), O (red), and Ca (blue) $z$ position vs. time for (a) pure EC and (b) pure THF on Ca anode. Corresponding starting and ending simulation snapshots are provided in (c) and (d), respectively. The common, two-step decomposition of EC (e) is contrasted with the lesser-seen concerted mechanism (f).

decomposition products, as described in the previous section, were still present; in particular, this materialized as a Ca-O-C matrix for EC and an absence of products for THF. Very similar results were observed for $\mathrm{Ca}\left(\mathrm{BH}_{4}\right)_{2}$, as this proved to be the least reactive salt; all anions remained intact throughout both EC and THF simulations, meaning that the inorganic products were unaffected by the presence of this salt. The only instance of $\mathrm{BH}_{4}^{-}$decomposition was observed due to the unphysically close initial positions of one $\mathrm{EC}$ and $\mathrm{BH}_{4}^{-}$anion, leading to the anion's loss of two $\mathrm{H}$ atoms; this can be seen in Figure 4(a) between 25 and $30 \AA$, where certain $\mathrm{H}$ atoms appear several angstroms away from any $\mathrm{B}$ atoms. Because this was due to an unphysical starting position, this reaction provides little insight into the true behavior of $\mathrm{Ca}\left(\mathrm{BH}_{4}\right)_{2}$, which otherwise proved to be stable. The remaining salts displayed at least one of two distinct decomposition modes identified in Table 1. It was more common to observe decomposition in solution, forming $\mathrm{CaF}^{+}, \mathrm{CaCl}^{+}, \mathrm{CaO}, \mathrm{BF}_{3}$, and $\mathrm{BCl}_{3}$. These products were observed in all remaining salts, often forming during solvent equilibration without anode exposure. In certain cases, if such a partially reacted salt pair was in proximity to an intact pair, the compounds would come together and form a conglomerate centered around a $\mathrm{Ca}-\mathrm{X}-\mathrm{Ca}$ bond. Figures 4(j) and $4(\mathrm{k})$ show examples of the resulting product in $\mathrm{THF} / \mathrm{Ca}\left(\mathrm{BCl}_{4}\right)_{2}$ and $\mathrm{THF} / \mathrm{Ca}\left(\mathrm{ClO}_{4}\right)_{2}$. The second mode of salt degradation constituted complete anion decomposition at the anode surface, observed for $\mathrm{BCl}_{4}^{-}$and $\mathrm{ClO}_{4}^{-}$; sample reaction products for the latter are shown in Figure 4(i). Although $\mathrm{Ca}-\mathrm{B}, \mathrm{Ca}-\mathrm{Cl}$, and $\mathrm{Ca}-\mathrm{O}$ bonds resulted, only $\mathrm{O}$ atoms diffused into the anode bulk at significant rates. While there is evidence of $\mathrm{B}$ and $\mathrm{Cl}$ atoms diffusing under the outer Ca layer in either solvent, these interactions are much less invasive and less frequent than with $\mathrm{O}$ atoms. This difference 


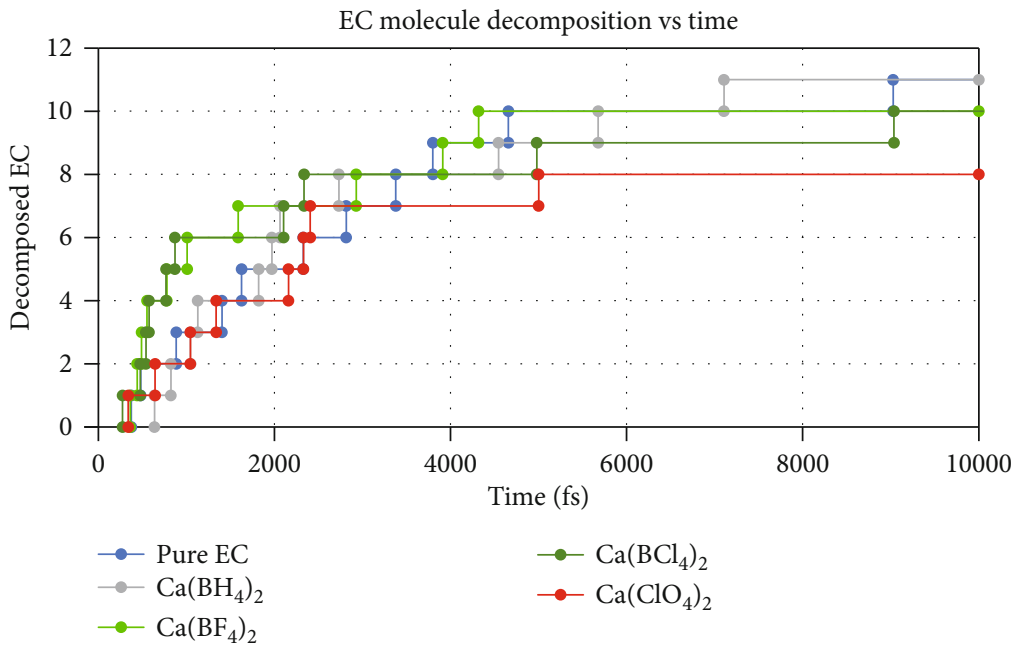

Figure 3: EC decomposition for pure $\mathrm{EC}$ and $\mathrm{EC}$ with $\mathrm{Ca}\left(\mathrm{BH}_{4}\right)_{2}, \mathrm{Ca}\left(\mathrm{BF}_{4}\right)_{2}, \mathrm{Ca}\left(\mathrm{BCl}_{4}\right)_{2}$, and $\mathrm{Ca}\left(\mathrm{ClO}_{4}\right)_{2}$. While $\mathrm{Ca}\left(\mathrm{ClO}_{4}\right)_{2}$ results in decreased $\mathrm{EC}$ decomposition, this effect is only due to anode passivation via decomposed salt molecules.

TABLE 1: Summary of decomposition products identified in each electrolyte trajectory. The first three columns report the number and products of decomposed solvent molecules, anions in solution, and anions at the anode surface. The final column records dissociated ion pairs. The final two rows include values for primary and secondary trajectories separated by a semicolon.

\begin{tabular}{|c|c|c|c|c|c|c|c|c|}
\hline & \multirow{2}{*}{ Salt } & \multicolumn{2}{|c|}{ Solvent molecules } & \multicolumn{2}{|c|}{ Anions (solution) } & \multicolumn{2}{|c|}{ Anions (surface) } & \multirow{2}{*}{ Ion pairs } \\
\hline & & Count & Products & Count & Products & Count & Products & \\
\hline \multirow{6}{*}{$\mathrm{EC}$} & $\mathrm{BH}_{4}$ & 11 & $\begin{array}{c}\mathrm{C}_{2} \mathrm{H}_{4} \mathrm{O}_{2}^{2-}, \mathrm{CO} \\
\mathrm{Ca}-\mathrm{C}, \mathrm{Ca}-\mathrm{O}\end{array}$ & 0 & - & 0 & - & 0 \\
\hline & $\mathrm{BF}_{4}$ & 10 & $\begin{array}{c}\mathrm{C}_{2} \mathrm{H}_{4} \mathrm{O}_{2}^{2-}, \mathrm{CO} \\
\mathrm{Ca}-\mathrm{C}, \mathrm{Ca}-\mathrm{O} \\
\mathrm{CO}_{3}^{2-}, \mathrm{C}_{2} \mathrm{H}_{4}\end{array}$ & 1 & $\mathrm{CaF}^{+}, \mathrm{BF}_{3}$ & 0 & - & 1 \\
\hline & & & $\mathrm{C}_{2} \mathrm{H}_{4} \mathrm{O}_{2}^{2-}, \mathrm{CO}$ & & & & & \\
\hline & $\mathrm{BCl}_{4}$ & 10 & $\begin{array}{l}\mathrm{Ca}-\mathrm{C}, \mathrm{Ca}-\mathrm{O} \\
\mathrm{CO}_{3}{ }^{2-}, \mathrm{C}_{2} \mathrm{H}_{4}\end{array}$ & 2 & $\mathrm{CaCl}^{+}, \mathrm{BCl}_{3}$ & 1 & Ca-B & 0 \\
\hline & & & $\mathrm{C}_{2} \mathrm{H}_{4} \mathrm{O}_{2}^{2-}, \mathrm{CO}$ & & & & & \\
\hline & $\mathrm{ClO}_{4}$ & 8 & $\begin{array}{l}\mathrm{Ca}-\mathrm{C}, \mathrm{Ca}-\mathrm{O} \\
\mathrm{CO}_{3}{ }^{2-}, \mathrm{C}_{2} \mathrm{H}_{4}\end{array}$ & 1 & $\mathrm{CaO}, \mathrm{ClO}_{3}$ & 2 & $\mathrm{Ca}-\mathrm{Cl}, \mathrm{Ca}-\mathrm{O}$ & 0 \\
\hline \multirow{4}{*}{ THF } & $\mathrm{BH}_{4}$ & 0 & - & 0 & - & 0 & - & 1 \\
\hline & $\mathrm{BF}_{4}$ & 0 & - & 1 & $\mathrm{CaF}^{+}, \mathrm{BF}_{3}$ & 0 & - & 1 \\
\hline & $\mathrm{BCl}_{4}$ & $1 ; 0$ & None; $\mathrm{C}_{4} \mathrm{H}_{8} \mathrm{OB}$ & $2 ; 2$ & $\begin{array}{l}\mathrm{CaCl}^{+}, \mathrm{BCl}_{3} \\
\mathrm{CaCl}_{2}, \mathrm{BCl}_{2}^{+}\end{array}$ & $2 ; 1$ & $\begin{array}{l}\mathrm{Ca}-\mathrm{Cl}, \\
\mathrm{Ca}-\mathrm{B}\end{array}$ & $0 ; 0$ \\
\hline & $\mathrm{ClO}_{4}$ & $0 ; 0$ & - & $1 ; 0$ & $\mathrm{CaO}, \mathrm{ClO}_{3}$ & $3 ; 1$ & $\mathrm{Ca}-\mathrm{Cl}, \mathrm{Ca}-\mathrm{O}$ & $0 ; 0$ \\
\hline
\end{tabular}

becomes clear when comparing Figures 4(c) and 4(g) with Figures 4(d) and 4(h). In all systems, the final anode composition was a combination of solvent and salt decomposition products at the anode surface, which are summarized in Table 1.

Although they differed in decomposition products, all salts exhibited some ion pair dissociation. It was common for an ion pair to dissociate at the anode surface without any decomposition, which was observed in $\mathrm{THF} / \mathrm{Ca}\left(\mathrm{BH}_{4}\right)_{2}$ and both $\mathrm{Ca}\left(\mathrm{BF}_{4}\right)_{2}$ trajectories. Both of these salts exhibited examples of undistorted anions infiltrating the upper layers of the anode, as can be seen in Figures 4(c) and 4(e). Degradation of salts, both in solvent and at the anode, could also separate ion pairs. At times, this could cause individual $\mathrm{Ca}$ atoms to incorporate into the anode, particularly evident around 9 ps and $37 \AA$ in Figure $4(\mathrm{~h})$, or leave the anode and enter solution, as observed at 1 ps and $17 \AA$ in Figure 4(b). Attempts to create solvent separated ion pairs (SSIPs) during solvent equilibration with $\mathrm{Ca}\left(\mathrm{BH}_{4}\right)_{2}$, the least reactive salt, were unsuccessful, as the individual ions always recombined within the first picosecond. This indicates that it is unlikely for SSIPs to form without the influence of the anode or decomposition reactions in the solvent. 


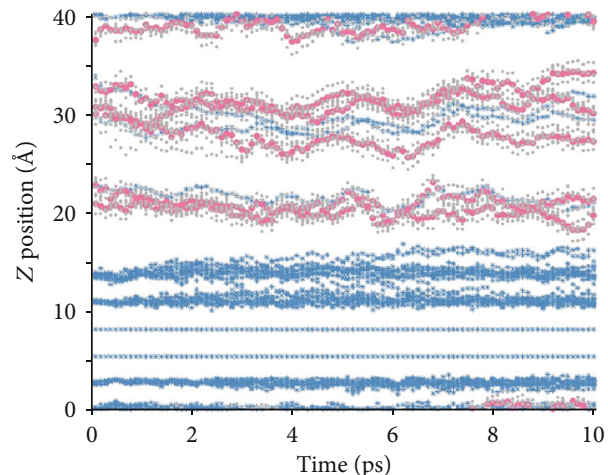

(a)

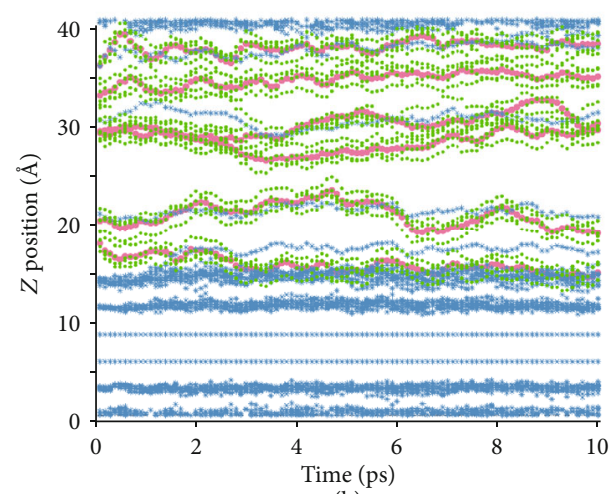

(b)

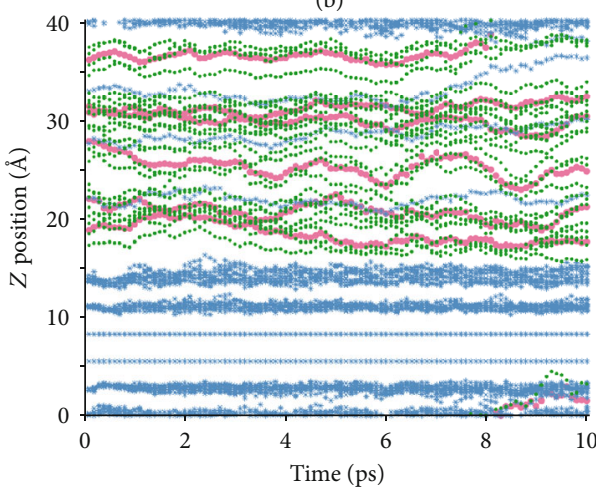

(c)

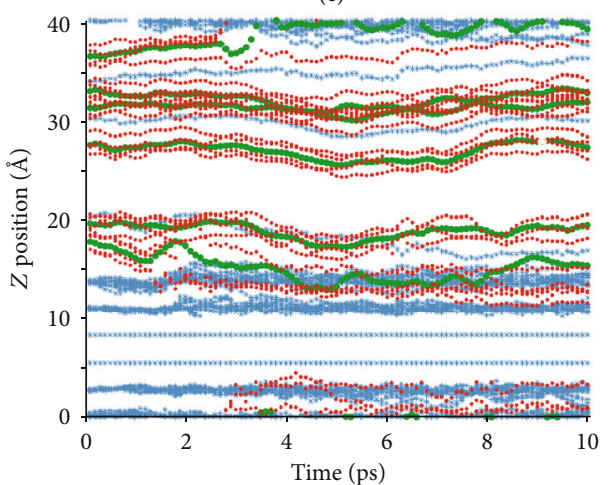

(d)

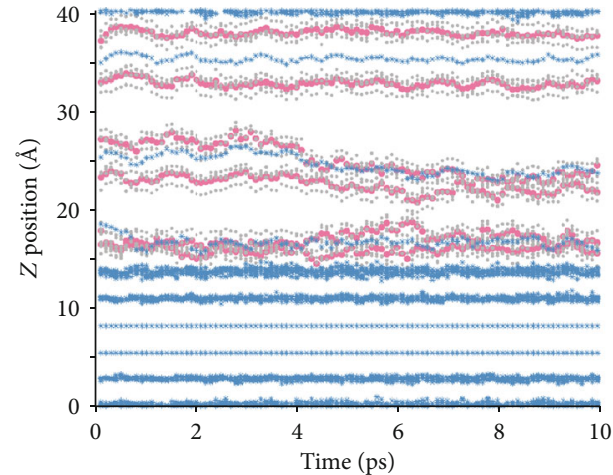

(e)

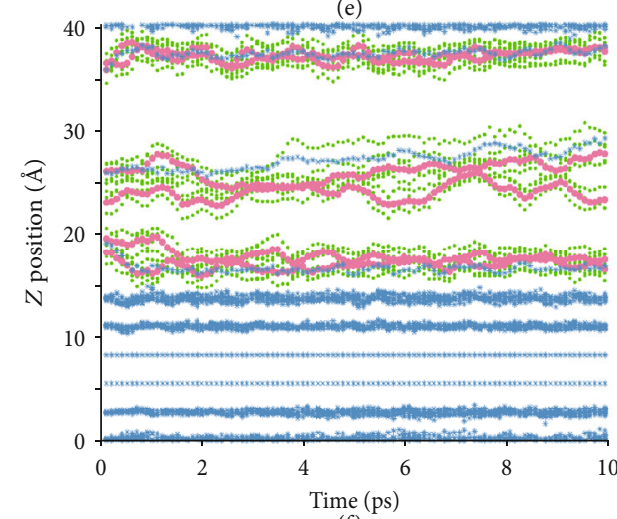

(f)

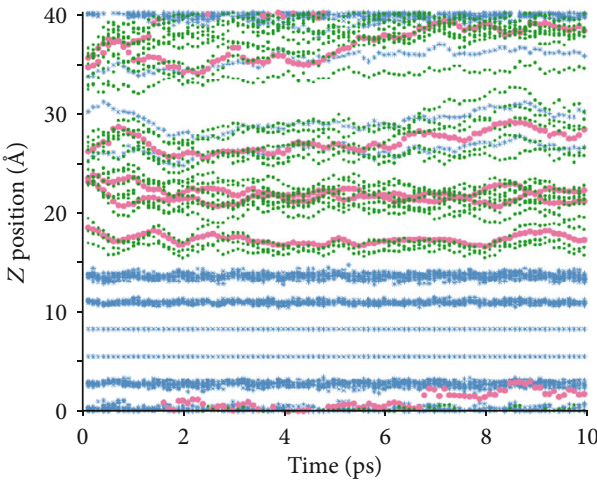

(g)

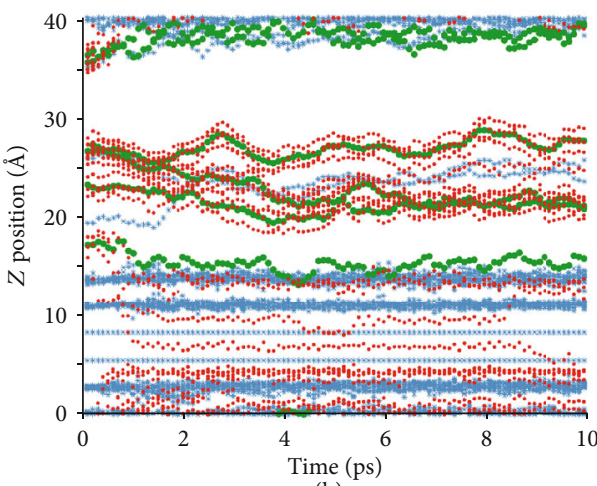

(h)

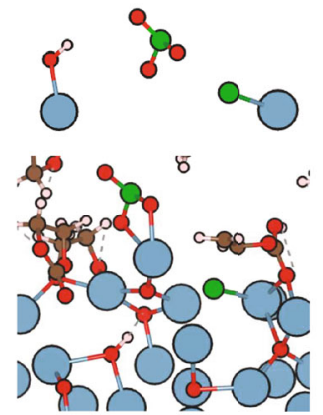

(i)

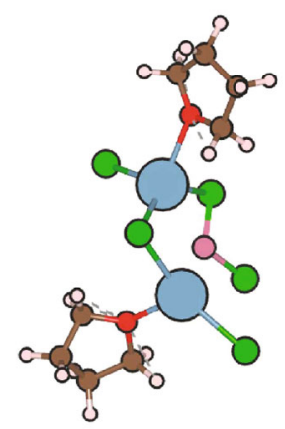

(j)

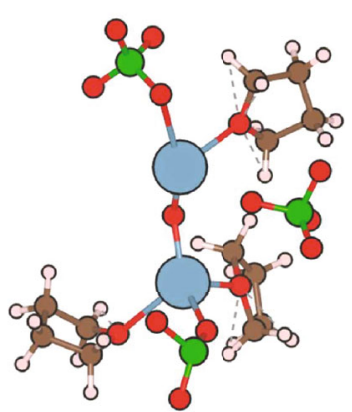

(k)

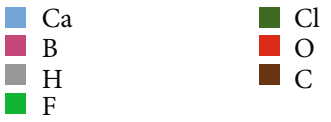

Figure 4: Salt atom and anode $z$ position vs. time for EC with (a) $\mathrm{Ca}\left(\mathrm{BH}_{4}\right)_{2}$, (b) $\mathrm{Ca}\left(\mathrm{BF}_{4}\right)_{2}$, (c) $\mathrm{Ca}\left(\mathrm{BCl}_{4}\right)_{2}$, and (d) $\mathrm{Ca}(\mathrm{ClO})_{2}$, as well as THF with analogous salts (e-h). Sample decomposition products are shown from (i) $\mathrm{EC} / \mathrm{Ca}\left(\mathrm{BCl}_{4}\right)_{2},(\mathrm{j}) \mathrm{THF} / \mathrm{Ca}\left(\mathrm{BCl}_{4}\right)_{2}$, and $(\mathrm{k}) \mathrm{THF} / \mathrm{Ca}(\mathrm{ClO})_{2}$. 
3.3. Charge Evolution: Single Molecule and System Wide. Next, we present an analysis of charge transfer at different scales in order to evaluate individual reactions as well as large-scale trends. First, we will analyze the simulation of pure EC, starting with an individual molecule and progressing to a system-wide analysis of the pure EC trajectory. Then, we will perform a similar analysis for THF, considering both neutral and gradually charged systems of pure THF solvent on a Ca anode. Because no THF decomposition was observed in these systems, we analyze singlemolecule decomposition as it was observed in the primary $\mathrm{Ca}\left(\mathrm{BCl}_{4}\right)_{2}$ trajectory.

Consider the most commonly observed EC decomposition reaction, a two-step reduction producing $\mathrm{CO}$ and $\mathrm{C}_{2} \mathrm{H}_{2} \mathrm{O}_{2}{ }^{2-}$. A single EC molecule was chosen from the pure EC trajectory and compared to an intact molecule in the same system during the former's decomposition. Figure 5(a) plots the length of both broken bonds in order to benchmark reaction progress relative to charge on constituent oxygen (Figure 5(b)) and carbon atoms (Figure 5(c)). Both carboxyl oxygens and the ester carbon get reduced in two separate steps across a $200 \mathrm{fs}$ timespan, producing $\mathrm{CO}^{-}$and $\mathrm{C}_{2} \mathrm{H}_{2} \mathrm{O}_{2}^{-}$, notably disagreeing with the formal charge assignment in the traditional reaction products used above. This charge distribution disagrees with prior theoretical investigations, which report charge transfer of approximately $1 e$ centered at only the ester carbon [29], although this discrepancy may be partially explained by the use of different charge analysis methods. Over $20 \mathrm{ps}$, all $\mathrm{CO}^{-}$migrate into the anode, where most are further reduced into individual $\mathrm{C}$ and $\mathrm{O}$ atoms. Those that stay intact maintain a charge of $-1.5 e$, while individual $\mathrm{C}$ and $\mathrm{O}$ atoms were reduced to $-1.7 \pm 0.1 e$ and $-1.1 \pm 0.1 e$, respectively. $\mathrm{C}_{2} \mathrm{H}_{2} \mathrm{O}_{2}{ }^{-}$remained on the surface with a charge of $-1.45 \pm 0.05 e$. Figure $\mathrm{S} 3$ provides a color map of the final snapshot of this trajectory, illustrating the varying levels of reduction experienced at each stage of EC decomposition. Figures 6(a)-6(c) offer multiple summaries of this trajectory, the first of which shows average charges on EC and the anode in $100 \mathrm{fs}$ steps. Observing Figure 6(a), it becomes clear that the majority of reduction occurs early in the simulation during initial molecule decomposition, slowing abruptly around $6 \mathrm{ps}$ and plateauing after the final EC decomposes around 9 ps. Electron transfer takes place between the outer anode layers and the solvent, while the fixed anode atoms remain electronically inactive. In a similar fashion, Figure 6(b) considers all 19 EC molecules individually. This figure reveals three terminal charge states for EC molecules in the simulation: stable in solution $(0 e)$, decomposed with intact $\mathrm{CO}^{-}(-3 e)$, and decomposed with bifurcated $\mathrm{CO}^{-}(-4 e)$. The final line around $-1.2 e$ shows the first step of EC decomposition. These trends slightly disagree with the results of Yamijala et al. who report a direct relation between the number of bonds broken in an EC molecule and the number of electrons transferred [39], contrasting with the extra electron localized on the $\mathrm{CO}^{-}$ molecule in Figure 6(b).

Unlike EC, there are very few examples of THF decomposition. However, an analogous analysis is still possible with the reaction observed in the primary $\mathrm{Ca}\left(\mathrm{BCl}_{4}\right)_{2}$ trajec- tory. The single decomposed THF molecule only underwent a net charge transfer of approximately $-0.7 e$, corresponding to a single broken ether bond. Of the two atoms involved in the bond, carbon gets reduced twice as much as oxygen, although this is partially due to the greater polarization of the $\mathrm{C} 1-\mathrm{C} 2$ bond, as labeled on the inset of Figure 5(d). Figures 5(e) and 5(f) show the charge transfer described above. Despite this reaction, THF remained stable in all other systems, even with the addition of significant charge. Figures $6(\mathrm{~d})$ and $6(\mathrm{~g})$ demonstrate the lack of redox activity in both neutral and gradually charged pure THF systems; even the addition of $-30 e$ does not prompt any reactions. Although charge on THF molecules may vary within a $0.2 e$ range (Figure 6(e)), this variation does not prompt any reactions, even with the increased spread in charge upon addition of electrons (Figure 6(h)). Yamijala et al. observed a similar lack of charge transfer for tetraethylene glycol dimethyl ether (G4) modeled on a $\mathrm{Ca}$ anode, indicating that a lack of charge transfer in a neutral system is associated with a lack of reactivity in a neutral system [39].

The stark differences in EC and THF behavior continue in Figures 6(c), 6(f), and 6(i). While Figure 6(f) merely confirms THF stability, Figures 6(c) and 6(i) show a huge discrepancy in THF and EC behavior in a reductive environment. In THF, the majority of excess electrons are placed on $\mathrm{H}$ atoms, which stabilize the charge across the entire molecule. Meanwhile, $\mathrm{C}$ and $\mathrm{O}$ atoms bear the majority of EC charge fluctuations; this concentrated charge results in broken bonds and solvent decomposition. Table 2 quantifies these data, showing that, despite their small average charge, the great number of $\mathrm{H}$ atoms in THF allows each molecule to carry a significant amount of charge without prompting decomposition.

The time-dependent density of state (TD-DOS) plots also support these findings (Fig. S4 of SI). The EC molecules that decompose within the time frame of interest develop distinct peaks at and immediately below the Fermi level. Meanwhile, the EC molecules that do not decompose within that time frame maintain peaks above the Fermi level and several electronvolts below the Fermi level. By contrast, the THF molecules never develop significant peaks immediately at the Fermi level. Those electrons that do present near the Fermi level are spread across many energies rather than in distinct peaked states as with the broken EC molecules. These observations suggest that electrons are distributed across THF as opposed to localized on a single bond, supporting the findings of Figure 6 and Table 2.

\section{Discussion}

Prior to discussing the implications of our findings, it is necessary to acknowledge the effects of simulation setup on the observed results. Variables such as sampling and system size can change final results and complicate comparisons between studies. Sampling of initial electrolyte configuration appears insignificant for solutions of pure solvent. We modeled our systems after Young et al. [29], including a nearidentical control simulation of EC solvent with Ca anode. Despite using a smaller number of solvent molecules (19 vs. 30) and different solvent preparation methods, both of 


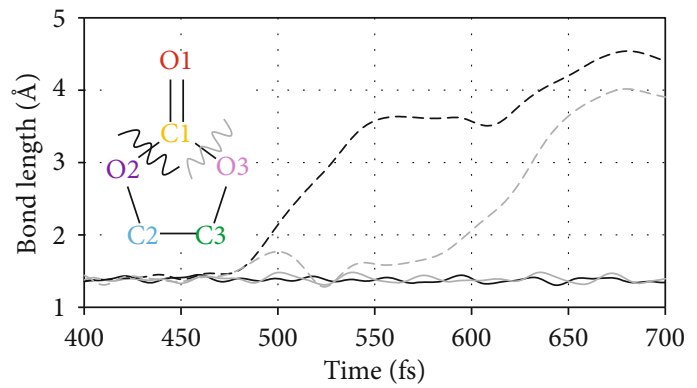

(a)

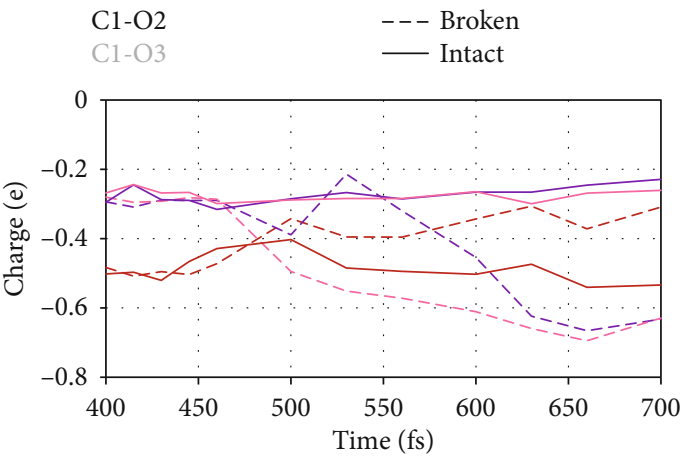

(b)

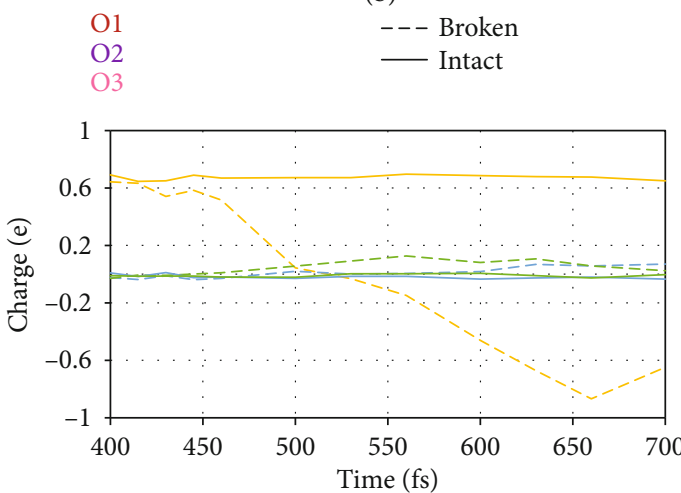

(c)

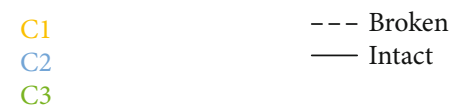

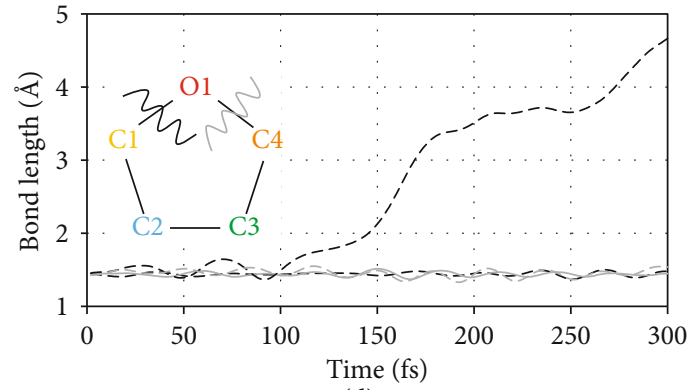

(d)

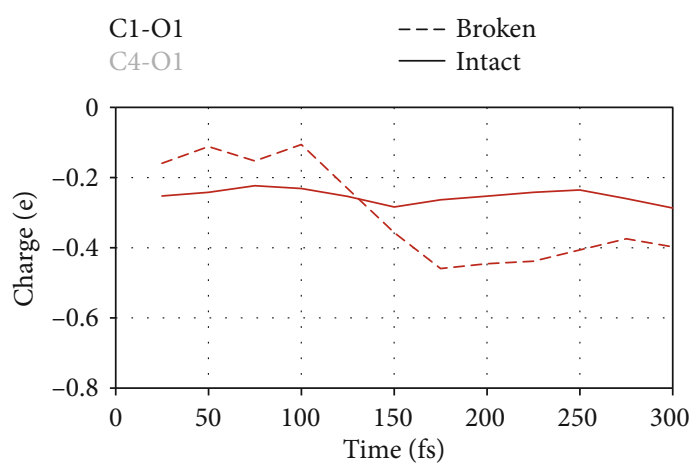

(e)

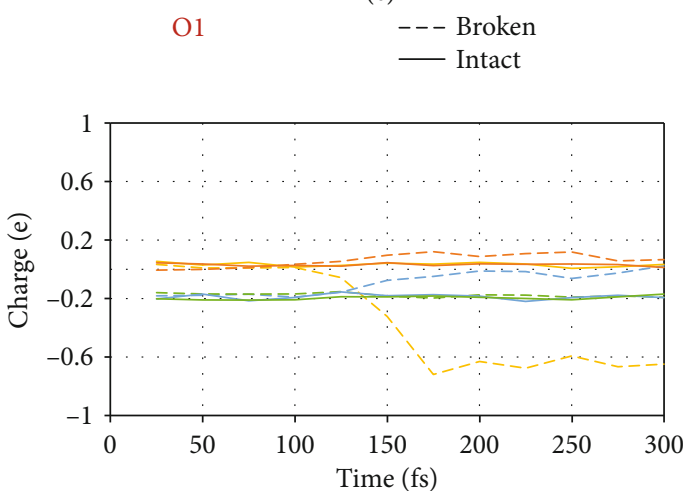

(f)

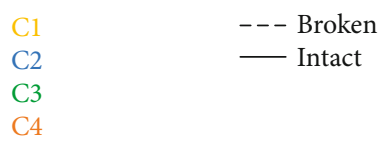

Figure 5: Detailed illustration of bond length and atomic charge during molecule decomposition for EC (a-c) and THF (d-f) relative to an intact reference. Bond lengths are provided as a measure of reaction progress in (a) and (d), where each respective inset clarifies atom and bond labeling. Charges on oxygen atoms are displayed in (b) and (e), while charges on carbon atoms are shown in (c) and (f).

our simulations yielded 11 decomposed molecules after $10 \mathrm{ps}$ at $450 \mathrm{~K}$. It appears that sampling is less significant for pure solvent simulations of this scale. Similarly, these results suggest that increasing the number of solvent molecules would not alter trajectory conclusions. As electrolyte decomposition requires direct contact with the electrode [9], this conclusion would likely hold assuming there are enough solvent molecules to coat both anode surfaces. However, this comparison does not allow an analysis of the effects of additional anode layers. Increasing anode thickness would add more $\mathrm{Ca}$ atoms to the system, providing more anode electrons to reduce the electrolyte. This would increase the number of reactions seen in the terminal stages of a simulation, when all available anode atoms have been oxidized. Thus, the following results only present a lower bound on the reactivity of the investigated electrolytes. The absence of a decomposition product does not rule out its possibility in a larger sized or longer duration simulation.

Unlike simulations with pure solvent, the addition of salts yields more complex results. We feature two trajectories with different initial configurations for THF/Ca( $\left(\mathrm{BCl}_{4}\right)_{2}$ and $\mathrm{THF} / \mathrm{Ca}\left(\mathrm{ClO}_{4}\right)_{2}$, chosen to test the reproducibility of THF and $\mathrm{ClO}_{4}^{-}$decomposition, respectively. While there is no direct comparison to be made for system size, discrepancies in both solvent and salt reactivity between the primary and secondary trajectories suggest that sampling strongly 


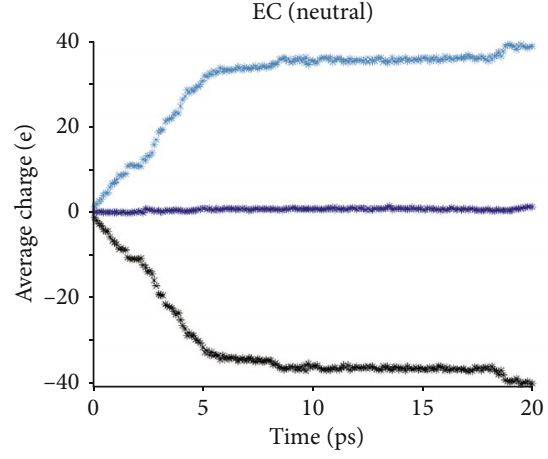

(a)

Ca (mobile)

$\mathrm{Ca}$ (fixed)

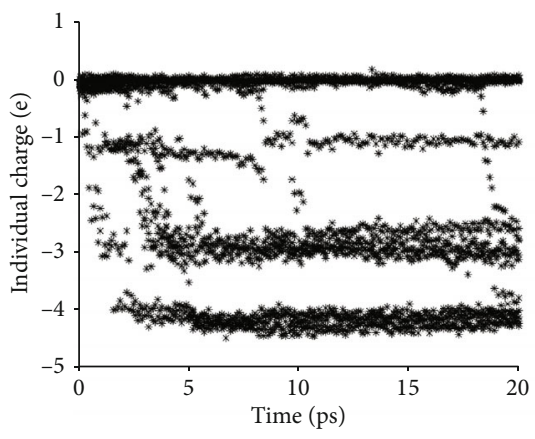

(b)

Solvent

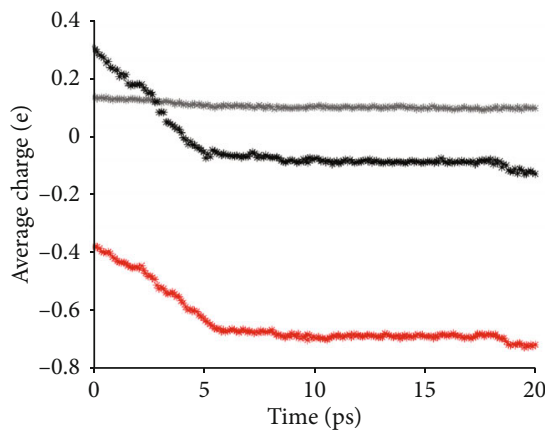

(c)

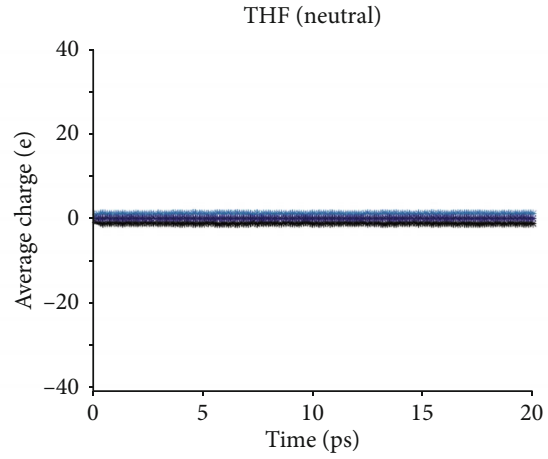

(d)

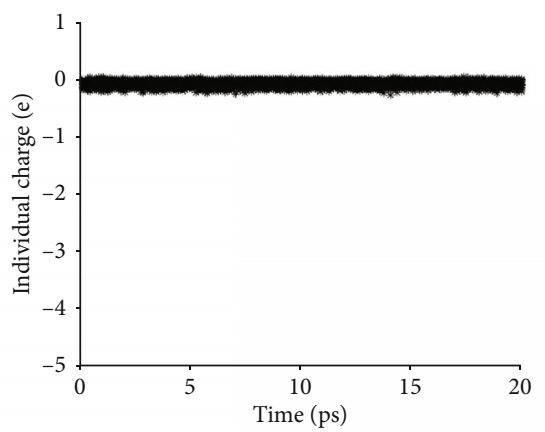

(e)

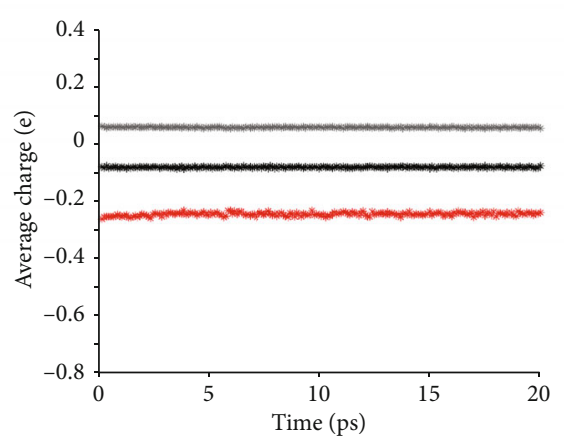

(f)

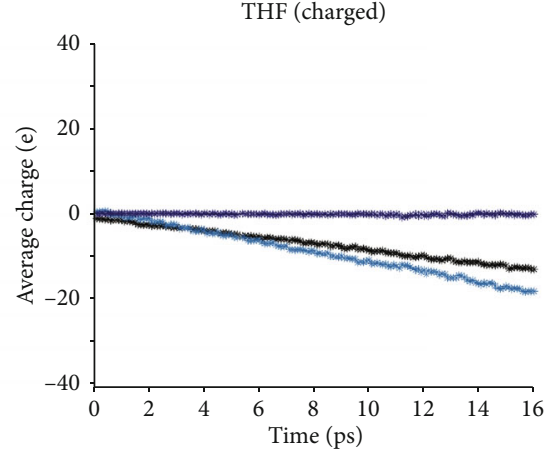

(g)

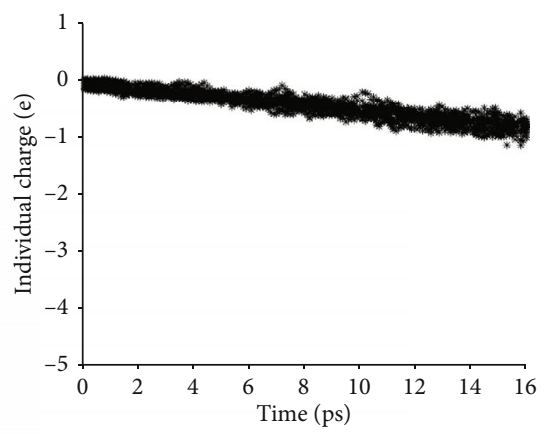

(h)

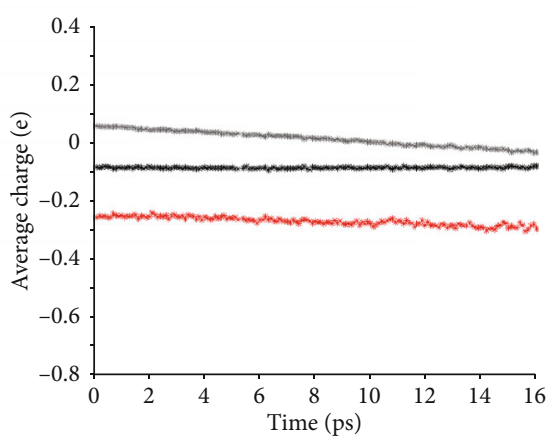

(i)

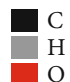

FIGURE 6: Charge evolution over time for systems of neutral EC in the first column (a-c), neutral THF in the second column (d-f), and gradually reduced THF in the third column ( $\mathrm{g}-\mathrm{i})$. Each row displays different values: in a descending order, these are the total charge on all solvent molecules, mobile anode atoms, and fixed anode atoms; the individual charge of each solvent molecule; and average charge on $\mathrm{C}$, $\mathrm{H}$, and $\mathrm{O}$ atoms.

influences the observed chemistry. In THF/Ca $\left(\mathrm{BCl}_{4}\right)_{2}$, the initial configuration determined whether THF decomposition occurred, while in $\mathrm{THF} / \mathrm{Ca}\left(\mathrm{ClO}_{4}\right)_{2}$, changes in anion proximity to the anode resulted in a difference of $3 \mathrm{ClO}_{4}{ }^{-}$ decompositions, equal to half the total anions in the system. With this limitation in mind, our results can still provide insight into early decomposition reactions at an unbiased, uncontaminated interface.
Certain decomposition patterns were always present with a given electrolyte. In the case of EC, this was rapid decomposition upon contact with the anode to form $\mathrm{C}_{2} \mathrm{H}_{4} \mathrm{O}_{2}{ }^{2-}$ and $\mathrm{CO}$. After the addition of $\mathrm{Ca}\left(\mathrm{BF}_{4}\right)_{2}$, $\mathrm{Ca}\left(\mathrm{BCl}_{4}\right)_{2}$, or $\mathrm{Ca}\left(\mathrm{ClO}_{4}\right)_{2}$, a minority of $\mathrm{EC}$ molecules decomposed via an alternative pathway to form $\mathrm{C}_{2} \mathrm{H}_{4}$ and $\mathrm{CO}_{3}^{2-}$. In prior studies, this transition has been observed with $\mathrm{Ca}\left(\mathrm{ClO}_{4}\right)_{2}$ but not $\mathrm{Ca}\left(\mathrm{PF}_{6}\right)_{2}[29,40]$. The difference 
TABLE 2: Average change in charge of $\mathrm{H}, \mathrm{O}$, and $\mathrm{C}$ atoms for neutral EC and charged THF from the beginning to the end of each respective trajectory. Change in charge is reported per atom and per molecule.

\begin{tabular}{lccccccr}
\hline & \multicolumn{2}{c}{$\mathrm{H}(\Delta e)$} & \multicolumn{2}{c}{$\mathrm{O}(\Delta e)$} & \multicolumn{2}{c}{$\mathrm{C}(\Delta e)$} & Total $(\Delta e)$ \\
\hline EC (neutral) & -0.03 & -0.12 & -0.25 & -0.75 & -0.30 & -0.90 & -1.77 \\
THF (charged) & -0.05 & -0.40 & -0.03 & -0.03 & -0.005 & -0.02 & -0.45 \\
\hline
\end{tabular}

in mechanisms is driven by kinetics of electron transfer: the presence of multiple EC molecules slows reduction, which favors the $\mathrm{CO}$ path [29]. This suggests that $\mathrm{Ca}\left(\mathrm{BH}_{4}\right)_{2}$ and $\mathrm{Ca}\left(\mathrm{PF}_{6}\right)_{2}$, where only the $\mathrm{CO}$ products are seen, slow electron transfer, while $\mathrm{Ca}\left(\mathrm{BF}_{4}\right)_{2}, \mathrm{Ca}\left(\mathrm{BCl}_{4}\right)_{2}$, and $\mathrm{Ca}\left(\mathrm{ClO}_{4}\right)_{2}$ speed it up. The transition in EC decomposition mechanisms can also be spurred by increased simulation temperatures, which increases electron transfer kinetics and results in greater decomposition of EC molecules through the alternative pathway [39]. Although this mechanism only affects one to two EC molecules in each system, it still accounts for $10-20 \%$ of all solvent-derived decomposition products and should be considered when choosing salts and analyzing interface components. In all simulations, all decomposition products remained at the anode surface with the exception of $\mathrm{CO}$, which interacted with the $\mathrm{Ca}$ anode to form a CaC-O matrix. Notably, our stoichiometry of a 1:1 C:O ratio in the anode disagrees with experimental characterization. Only $\mathrm{CaO}$ and $\mathrm{CaCO}_{3}$ have been reported in the SEI formed from electrolytes of EC/PC with $\mathrm{Ca}(\mathrm{TFSI})_{2}$ or $\mathrm{Ca}\left(\mathrm{BF}_{4}\right)_{2}$ salt [26], suggesting much higher levels of oxygen in the anode. This discrepancy may be due to atmospheric contamination in experiment or further decomposition of electrolyte observed at different potentials or longer time scales. Forero-Saboya et al. assert that $\mathrm{CaO}$ is conductive to $\mathrm{Ca}^{2+}$ at room temperature while $\mathrm{CaCO}_{3}$ is not [26], necessitating further investigation into the factors that control the ratio of these two compounds.

By contrast, THF showed little decomposition, in agreement with experiment. Neither Li et al. nor Wang et al. report organic decomposition products in the electrolyteanode interface in a THF/Ca $\left(\mathrm{BH}_{4}\right)_{2}$ solution $[10,13]$, and Campbell et al. report no reduction of THF even at $-2 \mathrm{~V}$ vs. $\mathrm{Li}_{/} / \mathrm{Li}^{+}$[41]. When using the same salt and solvent, Jie et al. communicated the presence of unspecified organic THF decomposition products as well as $\mathrm{CaCO}_{3}$, but we do not observe any such products. The latter discrepancy could stem from atmospheric contamination, which is known to cause $\mathrm{CaCO}_{3}$ formation [9]. Although we observed a single instance of THF reduction, this was with $\mathrm{Ca}\left(\mathrm{BCl}_{4}\right)_{2}$ rather than $\mathrm{Ca}\left(\mathrm{BH}_{4}\right)_{2}$. It is possible that that $\mathrm{BCl}_{4}{ }^{-}$catalyzed the reaction, corroborating the above statement that $\mathrm{Ca}\left(\mathrm{BCl}_{4}\right)_{2}$ accelerates solvent reduction. Following the same analysis, $\mathrm{Ca}\left(\mathrm{BF}_{4}\right)_{2}$ and $\mathrm{Ca}\left(\mathrm{ClO}_{4}\right)_{2}$ may also encourage THF decomposition. As there is no experimental comparison available for these electrolytes, it is difficult to comment on THF reduction and the eventual formation of the borate compound shown in Figure 4 beyond advising that it may be present at the anodeelectrolyte interface in such a system. Forero-Saboya et al. state that organic products are favorable for Ca-ion diffusion, sug- gesting that even if present, THF decomposition products should not hinder battery cycling [26].

The difference in EC and THF stability is typical of organic carbonates and ethers. Carbonates tend to have higher anodic stability, making them the electrolyte of choice for Li-ion batteries despite their decreased cathodic stability [42]. Broadly speaking, carbonates are more likely to decompose into a range of products in LIBs, including ROCOOLi, $\mathrm{Li}_{2} \mathrm{CO}_{3}$, and $\mathrm{Li}_{2} \mathrm{O}$ [42], analogous to the products cited above for CIB half cells using an EC-based solvent. In contrast to carbonates, ethers have lower anodic stability but improved reductive stability-this is likely the reason for the difference in reactivity seen between EC and THF in our simulations $[5,42]$. Similar simulations contrasting EC, PC, and G4 on a Ca anode have shown exceptional stability of the ether electrolyte, attributing this to its higher reductive stability [39]. Our results reveal that charge distribution is an important facet of this dichotomy. As seen in Figures 6(c) and 6(i) and summarized in Table 2, excess charge is mostly localized on $\mathrm{H}$ atoms in THF, but $\mathrm{C}$ and $\mathrm{O}$ atoms in EC; this is likely a factor contributing to the stability of the former solvent, but further investigation is needed to determine whether this trend applies to ethers and carbonates is general.

If ethers do get reduced, they are more likely to form organic oligomers that evenly coat the anode [42]. As a generalization, ethers result in a more homogenous interphase that is more likely to conduct $\mathrm{Ca}^{2+}$, while carbonates are more likely to be stable at higher voltages. In addition to favorable decomposition products and a wide electrochemical stability window (ESW), an ideal CIB solvent must also have high Ca-ion solubility and mobility. As the former is correlated with a high dielectric constant, but the latter with a low one, it is difficult to find a solvent that meets both criteria [25]. Several techniques are available to meet this challenge, the simplest of which is mixing solvents to combine their favorable properties. This has long been done with LIBs [43] and has already been computationally [25] and experimentally $[5,7,11]$ implemented with CIBs. In certain cases, a mixture will have a greater ESW than either of its components [43]. The ESW can further be improved by adding electronegative functional groups such as fluorine onto solvent molecules $[43,44]$; this could potentially address the poor anodic stability of THF. Lastly, electrolyte additives can be used to alter the $\mathrm{Ca}^{2+}$ coordination environment and tune SEI components; there are already several examples of this approach with CIBs $[12,23,24]$. While solvent choice is a main roadblock in CIB development, promising preliminary results and an abundance of unexplored techniques suggest imminent improvements. 
While the solvent is significant in CIB performance, salt choice is equally as important when controlling electrolyte properties. Upon the addition of salts, the foremost effect is the appearance of additional inorganic decomposition products, many of which discourage $\mathrm{Ca}^{2+}$ diffusion. $\mathrm{Ca}\left(\mathrm{BH}_{4}\right)_{2}$ was the only salt that showed no evidence of such product formation; this is in stark contrast to experiment, where $\mathrm{BH}_{4}{ }^{-}$was oxidized to form $\mathrm{BH}_{3}$ and $\mathrm{H}^{-}$upon exposure of THF/Ca $\left(\mathrm{BH}_{4}\right)_{2}$ to a Ca metal surface, ultimately forming $\mathrm{CaH}_{2}[10,13]$. However, Jie et al. [12], observing an electrolyte of the same components, reported no $\mathrm{CaH}_{2}$ formation, raising into question the connection between this compound and the electrolyte. While no experimental data are available for $\mathrm{EC} / \mathrm{Ca}\left(\mathrm{BH}_{4}\right)_{2}$, it can be assumed that $\mathrm{CaH}_{2}$ would behave similarly in EC, as all salts presented identical stability in both EC and THF in our simulations. Whether it forms or not, the merit of $\mathrm{CaH}_{2}$ as an SEI component is uncertain; while it is ionically conductive $[24,26]$, it readily forms $\mathrm{Ca}(\mathrm{OH})_{2}$ and hydrogen gas upon exposure to water [15]. Although $\mathrm{Ca}(\mathrm{OH})_{2}$ is present in some examples of reversible plating and stripping, it has an uncertain effect on $\mathrm{Ca}^{2+}$ diffusion. It is possible that this transition could be controlled by the addition of fluorine, which has been shown to stabilize $\mathrm{CaH}_{2}$ [45], while $\mathrm{Ca}\left(\mathrm{BH}_{4}\right)^{2}$ has shown promising preliminary results, although its low anodic stability of $3 \mathrm{~V}$ vs. $\mathrm{Ca} / \mathrm{Ca}^{2+}[10]$ and discrepancies regarding $\mathrm{CaH}_{2}$ formation motivate further investigation.

While our simulations are inconclusive towards the formation of $\mathrm{Ca}\left(\mathrm{BH}_{4}\right)_{2}$ decomposition products, $\mathrm{Ca}\left(\mathrm{BF}_{4}\right)_{2}$, $\mathrm{Ca}\left(\mathrm{BCl}_{4}\right)_{2}$, and $\mathrm{Ca}\left(\mathrm{ClO}_{4}\right)_{2}$ show unequivocal evidence of $\mathrm{CaF}_{2}, \mathrm{CaCl}_{2}$, and $\mathrm{CaO}$, whether formed in solution or at the anode. As mentioned above, all salts showed similar behavior in both solvents. While $\mathrm{Ca}\left(\mathrm{BF}_{4}\right)_{2}$ did not decompose at the anode, it reacted in both EC and THF to form $\mathrm{BF}_{3}$ and $\mathrm{CaF}^{+}$, a precursor of $\mathrm{CaF}_{2}$. This agrees with Ponrouch et al., who observed $\mathrm{CaF}_{2}$ formation during reversible Ca-ion plating and stripping in an electrolyte of $\mathrm{Ca}\left(\mathrm{BF}_{4}\right)_{2}$ in $\mathrm{EC} / \mathrm{PC}$ [7]. There are several other examples of reversible Ca-ion plating and stripping in the presence of $\mathrm{CaF}_{2}[13$, 24]. While this compound is not ionically conductive, Forero-Saboya et al. speculate that its clustered morphology results in space charge accumulation, improving $\mathrm{Ca}^{2+}$ diffusion through the SEI [26]. These authors also suggest a mechanism for the formation of cross-linked boron polymers in EC derived from the $\mathrm{C}_{2} \mathrm{H}_{4} \mathrm{O}_{2}{ }^{2-}$ decomposition product; while we observed no such reactions, our simulations do not rule out their possibility.

Much like $\mathrm{Ca}\left(\mathrm{BF}_{4}\right)_{2}$, our data suggest that any electrolyte employing $\mathrm{Ca}\left(\mathrm{BCl}_{4}\right)_{2}$ would likely be limited by $\mathrm{CaCl}_{2}$ formation, which was evident both in solution and at the anode. This compound is not ionically conductive and has commonly been identified as the limiting factor in cells where it is present $[7,9,46]$. In EC, surface boron would likely react with EC and its decomposition products to form borate oxides, which are ionically conductive [26]; how these opposing interface components would lead to reversible plating and stripping is uncertain, as there is no experimental evidence available for comparison. $\mathrm{Ca}\left(\mathrm{ClO}_{4}\right)_{2}$ also shows $\mathrm{CaCl}_{2}$ formation in both solvents, which agrees with both experimental and theoretical results of $\mathrm{Ca}\left(\mathrm{ClO}_{4}\right)_{2}$ in $\mathrm{EC} / \mathrm{PC}$ and EC, respectively $[7,29]$. Rapid anion decomposition at the anode also results in $\mathrm{CaO}$, which, although ionically conductive, has not been experimentally reported. Thus far, all evidence suggests that $\mathrm{Ca}\left(\mathrm{ClO}_{4}\right)_{2}$ is unconducive to $\mathrm{Ca}$-ion plating and stripping due to its extremely reactive nature upon exposure to $\mathrm{Ca}$ metal. It must be noted that the $\mathrm{THF} / \mathrm{Ca}\left(\mathrm{ClO}_{4}\right)_{2}$ simulations are purely theoretical because of its incredibly low solubility [9].

While salt choice does have a significant impact on electrolyte decomposition products, it also affects the prevalence of salt ion pairs in the solution. It is commonly theorized that increased ion pairing dampens $\mathrm{Ca}^{2+}$ mobility and discourages plating and stripping [27]. As our simulations were not configured for diffusion investigations, we cannot directly comment on this question. Similarly, no correlation between dissociation and solvent selection was observed, likely due to the limited sampling of the study. Nevertheless, our results showcase several examples of salt ion pair dissociation, whether anodeor reaction-mediated. The former occurred when an ion pair contacted the anode and subsequently dissociated without decomposition, as was observed with $\mathrm{Ca}\left(\mathrm{BH}_{4}\right)_{2}$ and $\mathrm{Ca}\left(\mathrm{BF}_{4}\right)_{2}$. This could contribute to a facile plating process, as the dissociation indicates a readily weakened ionic complex at the anode surface [5]. The effects of reaction-mediated ion pair dissociation are harder to hypothesize, as this mechanism involves dissociation in the solvent triggered by ion pair decomposition. The resulting compounds should have unique effects on Ca ion mobility as well as plating and stripping. Considering the frequency of solvated ion pair decomposition-it was observed with all salts but $\mathrm{Ca}\left(\mathrm{BH}_{4}\right)_{2}$-further research is necessary to characterize the behavior of salt ion pairs in solution. At the present, there are several prevalent methods for controlling salt ion pairing. Salt concentration plays a key role in this phenomenon, as higher concentration increases the likelihood of ion pairing. However, higher salt concentrations may be reached with a minimal increase in ion pairing by adding large, electron-delocalizing groups onto salt anions. This decreases the anions' charge density, thereby minimizing cation-anion attraction in the solvent $[12,14$, $24,27]$. There remains a great deal of unexplored options in salt choice, creating a wealth of opportunity in creating the optimal CIB electrolyte.

\section{Conclusion}

Of all eight electrolytes tested, THF with $\mathrm{Ca}\left(\mathrm{BH}_{4}\right)_{2}$ proved to be the least reactive solution, revealing neither solvent nor salt decomposition throughout the simulation. The remaining combinations of solvent-THF or EC-and salt$\mathrm{Ca}\left(\mathrm{BH}_{4}\right)_{2}, \mathrm{Ca}\left(\mathrm{BF}_{4}\right)_{2}, \mathrm{Ca}\left(\mathrm{BCl}_{4}\right)_{2}$, or $\mathrm{Ca}\left(\mathrm{ClO}_{4}\right)_{2}$-showed formation of passivating decomposition products, including $\mathrm{CaF}_{2}, \mathrm{CaCl}_{2}, \mathrm{CaCO}_{3}$, and $\mathrm{CaO}$. Barring $\mathrm{CaO}$, none of these products are conductive to $\mathrm{Ca}^{2+}$ ions, and even $\mathrm{CaO}$ formation is necessarily accompanied by either $\mathrm{CaCl}_{2}$ or $\mathrm{CaCO}_{3}$, meaning all remaining solutions result in the formation of some ionically insulating compounds. The formation of calcium halides alone is not enough to disrupt anode bulk structures, while oxygen and carbon readily diffuse into the anode, 
suggesting a dichotomy in decomposition product behaviors. The least stable of all solutions, $\mathrm{EC}$ and $\mathrm{Ca}\left(\mathrm{ClO}_{4}\right)_{2}$ exhibited both patterns, with both solvent and salt rapidly decomposing upon anode contact. Assuming a strategy minimizing anode decomposition products, our results would favor THF/Ca $\left(\mathrm{BH}_{4}\right)_{2}$ and reject $\mathrm{EC} / \mathrm{Ca}\left(\mathrm{ClO}_{4}\right)_{2}$. Charge analysis revealed that the reductive stability of THF was associated with charge distribution along the hydrogens of its hydrocarbon backbone, contrasting with the immediate localization seen in EC; it may be desirable to replicate the traits of THF to improve stability in novel electrolytes. While it yields favorable interphase chemistry, further research is necessary to improve the electrochemical stability window (ESW) of $\mathrm{THF} / \mathrm{Ca}\left(\mathrm{BH}_{4}\right)_{2}$, which may be improved by fluorination of THF, mixing with other solvents, and employing higher stability salts. Our results also suggested several significant processes to consider for $\mathrm{Ca}^{2+}$ diffusion beyond ion pairing; while this is a commonly cited issue in CIB electrolytes, the effects of salt decomposition in solvent are rarely discussed. While we do not investigate these details, the baseline behavior established herein can be used as a starting point for crafting more sophisticated solutions. As evidenced by the development of the first full-cell rechargeable rocking chair CIBs $[14,22]$, increased efforts in electrolyte and interphase research preclude a bright future for CIBs.

\section{Data Availability}

All data are freely available upon reasonable request. This includes input and output files for all simulations, analysis codes, and graphed data.

\section{Conflicts of Interest}

The authors declare that there is no conflict of interest regarding the publication of this article.

\section{Authors' Contributions}

D. Liepinya drafted the manuscript and generated, analyzed, and interpreted the data. M. Smeu assisted with design, editing, and supervisory support.

\section{Acknowledgments}

This work was supported by the National Science Foundation Research Experiences for Undergraduates Program (DMR-1950555).

\section{Supplementary Materials}

Figure S1: total number of decomposed EC molecules over simulation run time. Figure S2: EC orientation at time of decomposition measured as the difference in $z$ position of the carbonyl oxygen and the rest of the molecules. Figure S3: the final step of the pure EC trajectory. The left image is colored according to charge, while the right image provides context for atom type. Figure S4: time-dependent DOS plots of THF $(a-c)$ and EC $(d-f)$ molecules. (Supplementary Materials)

\section{References}

[1] P. Canepa, G. Sai Gautam, D. C. Hannah et al., "Odyssey of multivalent cathode materials: open questions and future challenges," Chemical Reviews, vol. 117, no. 5, pp. 4287-4341, 2017.

[2] T. Chen, Y. Jin, H. Lv et al., "Applications of Lithium-Ion batteries in Grid-Scale energy storage systems," Transactions of Tianjin University, vol. 26, no. 3, pp. 208-217, 2020.

[3] B. Weiss and O. Michiyo, Environmental Risk Mitigation: Coaxing a Market in the Battery and Energy Supply and Storage Industry, Springer International Publishing, Cham, Switzerland, 2016.

[4] J. Muldoon, C. B. Bucur, and T. Gregory, "Quest for nonaqueous multivalent secondary batteries: magnesium and beyond," Chemical Reviews, vol. 114, no. 23, pp. 1168311720, 2014.

[5] Y. Liang, H. Dong, D. Aurbach, and Y. Yao, "Current status and future directions of multivalent metal-ion batteries," Nature Energy, vol. 5, no. 9, pp. 646-656, 2020.

[6] T. A. Pham, "Ab initio simulations of liquid electrolytes for energy conversion and storage," International Journal of Quantum Chemistry, vol. 119, no. 1, article e25795, 2019.

[7] A. Ponrouch, C. Frontera, F. Bardé, and M. R. Palacín, "Towards a calcium-based rechargeable battery," Nature Materials, vol. 15, no. 2, pp. 169-172, 2016.

[8] E. Peled, "The electrochemical behavior of alkali and alkaline earth metals in nonaqueous battery Systems-The solid electrolyte interphase model," Journal of the Electrochemical Society, vol. 126, no. 12, pp. 2047-2051, 1979.

[9] D. Aurbach, R. Skaletsky, and Y. Gofer, "The electrochemical behavior of calcium electrodes in a few organic electrolytes," Journal of the Electrochemical Society, vol. 138, no. 12, pp. 3536-3545, 1991.

[10] D. Wang, X. Gao, Y. Chen, L. Jin, C. Kuss, and P. G. Bruce, "Plating and stripping calcium in an organic electrolyte," Nature Materials, vol. 17, pp. 16-20, 2018.

[11] S. Biria, S. Pathreeker, H. Li, and I. D. Hosein, "Plating and stripping of calcium in an alkyl carbonate electrolyte at room temperature," ACS Applied Energy Materials, vol. 2, no. 11, pp. 7738-7743, 2019.

[12] Y. Jie, Y. Tan, L. Li et al., "Electrolyte solvation manipulation enables unprecedented room-temperature calcium-metal batteries," Angewandte Chemie - International Edition, vol. 59, no. 31, pp. 12689-12693, 2020.

[13] Z. Li, O. Fuhr, M. Fichtner, and Z. Zhao-Karger, "Towards stable and efficient electrolytes for room-temperature rechargeable calcium batteries," Energy and Environmental Science, vol. 12, no. 12, pp. 3496-3501, 2019.

[14] K. V. Nielson, J. Luo, and T. L. Liu, "Optimizing calcium electrolytes by solvent manipulation for calcium batteries," Batteries \& Supercaps, vol. 3, no. 8, pp. 766-772, 2020.

[15] X. Gao, X. Liu, A. Mariani et al., "Alkoxy-functionalized ionic liquid electrolytes: understanding ionic coordination of calcium ion speciation for the rational design of calcium electrolytes," Energy and Environmental Science, vol. 13, no. 8, pp. 2559-2569, 2020.

[16] S. Biria, S. Pathreeker, F. S. Genier, H. Li, and I. D. Hosein, "Plating and stripping calcium at room temperature in an ionic-liquid electrolyte," ACS Applied Energy Materials, vol. 3, no. 3, pp. 2310-2314, 2020. 
[17] C. S. Martinez-Cisneros, A. Fernandez, C. Antonelli et al., "Opening the door to liquid-free polymer electrolytes for calcium batteries," Electrochimica Acta, vol. 353, p. 136525, 2020.

[18] R. Y. Wang, C. D. Wessells, R. A. Huggins, and Y. Cui, "Highly reversible open framework nanoscale electrodes for divalent ion batteries," Nano Letters, vol. 13, no. 11, pp. 5748-5752, 2013.

[19] A. L. Lipson, B. Pan, S. H. Lapidus, C. Liao, J. T. Vaughey, and B. J. Ingram, "Rechargeable Ca-ion batteries: a new energy storage system," Chemistry of Materials, vol. 27, no. 24, pp. 8442-8447, 2015.

[20] P. Padigi, G. Goncher, D. Evans, and R. Solanki, "Potassium barium hexacyanoferrate - A potential cathode material for rechargeable calcium ion batteries," Journal of Power Sources, vol. 273, pp. 460-464, 2015.

[21] T. Tojo, Y. Sugiura, R. Inada, and Y. Sakurai, "Reversible calcium ion batteries using a dehydrated Prussian blue analogue cathode," Electrochimica Acta, vol. 207, pp. 22-27, 2016.

[22] T. N. Vo, J. Hur, and I. T. Kim, "Enabling high performance calcium-ion batteries from Prussian blue and metal-organic compound materials," ACS Sustainable Chemistry and Engineering, vol. 8, no. 7, pp. 2596-2601, 2020.

[23] K. Ta, R. Zhang, M. Shin, R. T. Rooney, E. K. Neumann, and A. A. Gewirth, "Understanding Ca electrodeposition and speciation processes in nonaqueous electrolytes for nextgeneration Ca-ion batteries," ACS Applied Materials and Interfaces, vol. 11, no. 24, pp. 21536-21542, 2019.

[24] A. Shyamsunder, L. E. Blanc, A. Assoud, and L. F. Nazar, "Reversible calcium plating and stripping at room temperature using a borate salt," ACS Energy Letters, vol. 4, no. 9, pp. 2271-2276, 2019.

[25] M. Shakourian-Fard, G. Kamath, S. M. Taimoory, and J. F. Trant, "Calcium-ion batteries: identifying ideal electrolytes for next-generation energy storage using computational analysis," Journal of Physical Chemistry C, vol. 123, no. 26, pp. 15885-15896, 2019.

[26] J. Forero-Saboya, C. Davoisne, R. Dedryvère, I. Yousef, P. Canepa, and A. Ponrouch, "Understanding the nature of the passivation layer enabling reversible calcium plating.," Energy and Environmental Science, vol. 13, no. 10, pp. 34233431, 2020.

[27] D. S. Tchitchekova, D. Monti, P. Johansson et al., "On the reliability of half-cell tests for monovalent $(\mathrm{Li}+, \mathrm{Na}+)$ and divalent $(\mathrm{Mg} 2+, \mathrm{Ca} 2+)$ cation based batteries," Journal of the Electrochemical Society, vol. 164, no. 7, pp. A1384-A1392, 2017.

[28] A. Ponrouch and M. R. Palacin, "On the road toward calciumbased batteries," Current Opinion in Electrochemistry, vol. 9, pp. 1-7, 2018.

[29] J. Young and M. Smeu, "Ethylene carbonate-based electrolyte decomposition and solid-electrolyte interphase formation on Ca metal anodes," Journal of Physical Chemistry Letters, vol. 9, no. 12, pp. 3295-3300, 2018.

[30] R. Car and M. Parrinello, "Unified approach for molecular dynamics and density-functional theory," Physical Review Letters, vol. 55, no. 22, pp. 2471-2474, 1985.

[31] G. Kresse and J. Hafner, "Ab initiomolecular dynamics for liquid metals," Physical Review B, vol. 47, no. 1, pp. 558-561, 1993.

[32] G. Kresse and J. Furthmuller, "Efficient iterative schemes forab initiototal-energy calculations using a plane-wave basis set," Physical Review B, vol. 54, no. 16, pp. 11169-11186, 1996.
[33] G. Kresse and J. Furthmuller, "Efficiency of ab-initio total energy calculations for metals and semiconductors using a plane-wave basis set," Computational Materials Science, vol. 6, no. 1, pp. 15-50, 1996.

[34] P. E. Blöchl, "Projector augmented-wave method," Physical Review B, vol. 50, no. 24, pp. 17953-17979, 1994.

[35] J. P. Perdew, A. Ruzsinszky, G. I. Csonka et al., "Restoring the density-gradient expansion for exchange in solids and surfaces," Physical Review Letters, vol. 100, pp. 1-4, 2008.

[36] L. E. Camacho-Forero and P. B. Balbuena, "Effects of charged interfaces on electrolyte decomposition at the lithium metal anode," Journal of Power Sources, vol. 472, article 228449, 2020.

[37] T. A. Manz and N. G. Limas, Eds., "Introducing DDEC6 atomic population analysis: part 1 . Charge partitioning theory and methodology," RSC Advances, vol. 6, no. 53, pp. 4777147801, 2016.

[38] N. G. Limas and T. A. Manz, "Introducing DDEC6 atomic population analysis: part 2. Computed results for a wide range of periodic and nonperiodic materials," RSC Advances, vol. 6, no. 51, pp. 45727-45747, 2016.

[39] S. S. Yamijala, H. Kwon, J. Guo, and B. M. Wong, "Stability of calcium ion battery electrolytes: predictions from ab initio molecular dynamics simulations," ACS Applied Materials and Interfaces, vol. 13, no. 11, pp. 13114-13122, 2021.

[40] J. Young, P. M. Kulick, T. R. Juran, and M. Smeu, "Comparative study of ethylene carbonate-based electrolyte decomposition at $\mathrm{Li}, \mathrm{Ca}$, and $\mathrm{Al}$ anode interfaces," ACS Applied Energy Materials, vol. 2, no. 3, pp. 1676-1684, 2019.

[41] S. A. Campbell, C. Bowes, and R. S. McMillan, "The electrochemical behaviour of tetrahydrofuran and propylene carbonate without added electrolyte," Journal of Electroanalytical Chemistry and Interfacial Electrochemistry, vol. 284, no. 1, pp. 195-204, 1990.

[42] D. Lin, Y. Liu, and Y. Cui, "Reviving the lithium metal anode for high-energy batteries," Nature Nanotechnology, vol. 12, no. 3, pp. 194-206, 2017.

[43] S. Tan, Y. J. Ji, Z. R. Zhang, and Y. Yang, "Recent progress in research on high-voltage electrolytes for lithium-ion batteries," ChemPhysChem, vol. 15, no. 10, pp. 1956-1969, 2014.

[44] E. Quartarone and P. Mustarelli, "Review-Emerging trends in the design of electrolytes for lithium and post-lithium batteries," Journal of the Electrochemical Society, vol. 167, no. 5, article 050508, 2020.

[45] R. Varunaa and P. Ravindran, "Structural phase stability in fluorinated calcium hydride," in AIP Conference Proceedings, Bhubaneswar, Odisha, India, 2017.

[46] R. J. Staniewicz, "A study of the calcium-thionyl chloride electrochemical system," Journal of The Electrochemical Society, vol. 127, no. 4, pp. 782-789, 1980. 